\title{
EMPIRICAL ANALYSIS OF REAL ESTATE FINANCIAL RISK IN WENZHOU
}

\author{
Wanhao Chang \\ Wenzhou Business College, P.R.China \\ Lichen Chou \\ Wenzhou Business College, P.R.China \\ $\mathrm{Bin} \mathrm{Hu}$ \\ Wenzhou Business College, P.R.China
}

\begin{abstract}
The risks of real estate finance are related to economic stability and financial development in a region. In Wenzhou real estate market, the falling house price and folk borrowing crash in recent years have increased the risks of real estate finance. Based on the data of Wenzhou statistical yearbook from 2001 to 2015, this paper makes an empirical analysis on the influence factors of the risks of Wenzhou real estate financial market and the speculation degree. The empirical results show: the falling sale price is the main factor of increasing risks of Wenzhou real estate finance; the speculation degree is high. Finally, this paper gives some suggestions to control the risks of Wenzhou real estate financial market.
\end{abstract}

Keywords: Real estate financial risk; Wenzhou; Empirical analysis

\section{JEL code: R33}

\section{Introduction}

Real estate financial risks exist in the home buyers, real estate development companies and the economic activities involving financial institutions, besides, it is closely relevant to local economy and financial development. So it's of great importance to control the risks of real estate finance in order to stabilize the financial industry and the regional economy. Wenzhou real estate market has maintained a steady growth for many years. In 2015, the gross investment in fixed assets reached 390.57 billion yuan, a 13 percent increase year on year; the gross investment in real estate development reached 90.2 billion yuan, a 17.7 percent increase year on year; additionally, the housing construction area reached 47.237 million square meters, a 1.6 percent increase year on year; the completed housing area reached 7.709 million square meters, a 29 percent increase year on year; the sale area of commercial housing reached 7.738 million square meters, a 47.2 percent increase year on year. Since March 2005, in order to stabilize the house price, Central Government of China and the local governments in China 
have introduced quite a number of macro-control policies and specific measures on real estate. Still, the falling house price, folk borrowing crash and rapidly increasing non-performing housing loans ratio of financial institutions in recent years have increased the risks of Wenzhou real estate finance. Therefore, the analysis on the risks of Wenzhou real estate finance makes great sense to control the risks of Wenzhou real estate finance.

\section{Literature review}

Most foreign scholars study the form of real estate financial risks from the following aspects: financial instability, the mistakes caused by government policies, the game among economic subjects and information asymmetry. In the financing of real estate enterprises, banks have always been the leaders. However, banking system is not strong, so it will bring about too close connection between real estate finance and banking system, which may cause further financial risks. Krugman (1999) thought that all of the real estate market bubbles had one thing in common: bank financing accounted for a large proportion. From 1983 to 1990, the proportion of real estate loans of American commercial banks in total loans increased from $30.6 \%$ to $41.5 \%$; in the net loan value added from 1985 to 1989 , the real estate loans accounted for $71.2 \%$.

The scholars in China study the forming reasons of real estate financial risks mainly from the following aspects: local governments, investors, home buyers, banks and other subjects. Lanying $\mathrm{Li}$ and Wei Li (2012) pointed out that the formation mechanism of real estate financial risk laid in the information asymmetry between real estate developers and banks, unsuccessful government regulation, unbalanced development of real estate market, excessive speculation in the market and so on. In the bank-dominated real estate economy, banks provide substantial capital for real estate industry and play a key role in the formation of real estate financial risks. Jianfei Li and Chenyu Shi (2005) verified the inevitable link between real estate price fluctuation and bank credit growth through empirical research, which credibly explained overheated real estate in China in recent years. Yue Zhang (2013) believed the financing channels of the real estate in China were single and highly dependent on bank indirect financing, which caused bigger credit risks hiding in real estate loans. And mortgage-backed securitization (MBS) guided by bank financial innovation may further aggravate real estate financial risks. Real estate was a key area of government macro-control. Besides, the government's improper macro policies and scarce financial supervision also exacerbated real estate financial risks. Xianrong Yi (2005) held the idea that the real estate in China was controlled by the government, and it did not realize the full market operation. As a result, the real estate without the real market operation was bound to have bubbles. 


\section{Analysis on the risks of Wenzhou real estate finance}

\subsection{Risk analysis based on home buyers}

\subsubsection{Price and Income Ratio}

Price and Income Ratio (PIR) refers to the ratio between the average price of real estate and residents' annual income, which is generally used to measure the risks when people buy houses and consumers' ability to buy houses. Due to the differences in regional economic development, consumption habits and consumption structure, there are also significant differences in Price and Income Ratio of provinces and cities. From the view of the average, the average Price and Income Ratio of house price in the world is between 6 to 8, while that in Wenzhou in 2015 was 9.13 and that in 50 Chinese large and medium-sized cities in 2015 was 9.15.In addition, the policies for regulating the real estate market in recent years contribute to controlling house price. As can be observed in the chart 1, the trend of Price and Income Ratio in Wenzhou is the same as that in 50 large and medium-sized cities, and it keeps a declining trend in recent years. However, the Price and Income Ratio in Wenzhou is higher than the average level in 50 large and medium-sized cities. This shows that Wenzhou local residents' pressure to buy a house has great influence on their life quality and daily expenses.

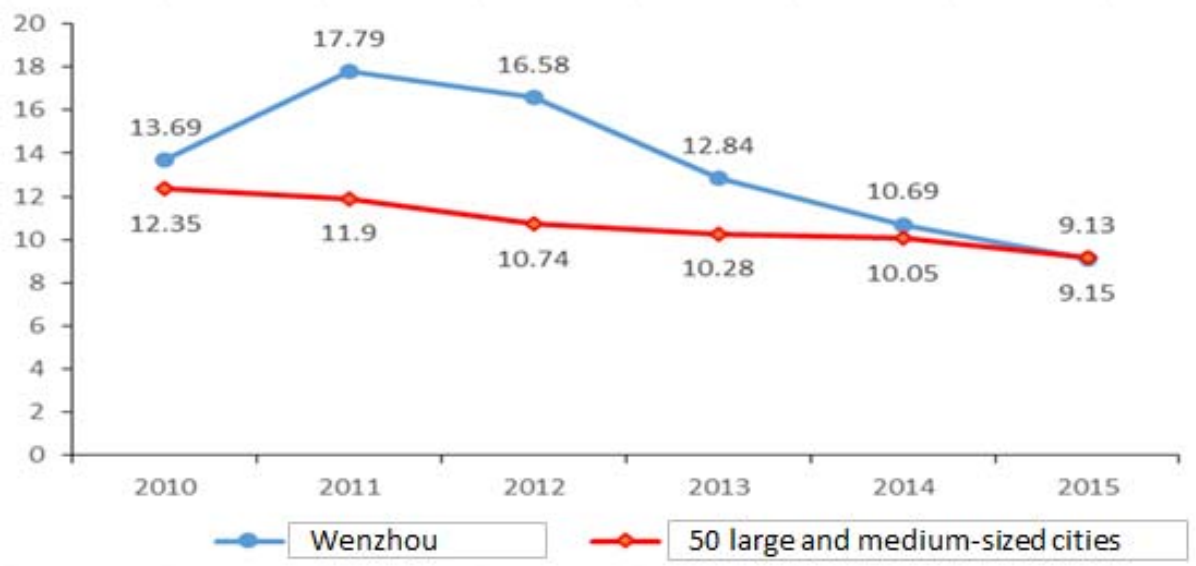

Figure 1. The variation trend of Price and Income Ratio in Wenzhou and 50 large and medium-sized cities

\subsubsection{The ratio between the balance of individual housing loans and GDP}

In 2017, the balance of individual housing loans in Wenzhou reached 136.88 billion yuan, a 25.8 percent increase year on year; new individual housing loans reached 20.88 billion yuan, accounting for $68.79 \%$ of new total RMB loans of 30.353 billion yuan in that year. In addition, the ratio between the balance of individual housing loans and GDP was 21.94\%, which was below the national average of $24.19 \%$ in China, and from the international view, the average ratio of EU was 39\%; that in UK and Germany were $60 \%$ and $47 \%$ respectively. Therefore, the ratio between the balance of individual housing loans and GDP in Wenzhou was lower, in a reasonable range. 
More importantly, in order to promote the development of the housing market, Wenzhou financial institutions adjust the minimum down payment for the first set of house to $20 \%$, second house to $30 \%$. The two proportions decrease by $10 \%$. At the same time, the proportion of individual housing loans will be continuously decreased, and the trough will be $4.36 \%$. These measures greatly contribute to increasing the balance of individual housing loans and residents' housing demand, and releasing the pressure of housing loans. And the increase in demand could urge real estate development companies to enhance the housing supply, so as to further promote the development of Wenzhou real estate. But from the perspective of the ratio between the balance of individual housing loans and GDP, the measures of Wenzhou financial institutions cause the rise of this ratio, thus increasing the financial risks of real estate.

In summary, from the view of home buyers, real estate financial risks mainly appear when invested real estate demand grows, which may lead to the excessively rapid growth of housing price, so as to increase residents' pressure to buy a house. Although residents can choose mortgage loans to alleviate the pressure, there are still huge financial risks.

\subsection{Risk analysis based on real estate development companies}

The financial structure of real estate developers is the main link that includes real estate financial risks, and the measurement index is asset-liability ratio. According to Wenzhou statistical yearbook in 2015, there are 223 real estate developers in Wenzhou, and 652 enterprises in the whole real estate industry. Real estate development companies have an asset-liability ratio of 61.53 percent, compared with the asset-liability ratio of 57.72 percent in the whole real estate industry. Due to the differences of real estate financial structure in different countries and regions. There are significant differences about the asset-liability ratio among real estate developers. From the perspective of international level, the asset-liability ratio in Japanese real estate development companies is more than $80 \%$; the ratio in the United States is more than $60 \%$; of course, the ratio in Hong Kong and Europe is relatively lower, in the range of $30 \%$ to $50 \%$. Therefore, the asset-liability ratio of Wenzhou real estate development companies remains at a relatively high level. For the industry with longer product cycle, like real estate, this phenomenon may bring about great risks. In particular, when there are half-way buildings in projects or problems in sales section, the companies are great likely to have a debt crisis, even causing the real estate financial risks.

\subsection{Risk analysis based on financing institutions}

According to statistics from CBRC Wenzhou Office, by February 2017, total real estate loans in Wenzhou have reached 164.749 billion yuan, a 15.1 percent increase year on year. In the meanwhile, it exceeded the growth rate of loans in Wenzhou (12.85\%). In addition, total loans in Wenzhou reached 774.7 billion yuan in the same phase, and the total real estate loans accounted for $18.3 \%$. From the international experience, in a lot of countries and regions, total real estate loans accounted for $30 \%$ to $50 \%$ proportion of total loans of financial institutions, this proportion in China is relatively low, especially compared with that in developed countries, far below the level in developed countries. Nonetheless, if real estate grows at a 
rapid rate, that proportion will rise soon, and then it catches up with the developed world. Now, real estate loans still account for a little, however, the loans of real estate development companies are mainly mortgage loans; part of the collateral is real estate, and other collateral is land assets. Once the real estate bubbles burst, the impact of financial institutions will be devastating. Therefore, current financial risks in real estate loan cannot be ignored.

\section{Empirical analysis}

\subsection{Empirical analysis on the influence factors of real estate financial risks}

\subsubsection{Variable selection and gist}

\subsubsection{Explained variable : The concentration ratio of real estate loans}

The concentration ratio of real estate loans refers to the ratio between the balance of real estate loans and total balance of the loans granted by banks. This index reflects the risks of real estate finance, and can be used to quantitatively measure the risks of Wenzhou real estate finance.

\subsubsection{Explaining variable : Average price of commercial housing and local GDP}

The price level of Wenzhou real estate market can be measured by the average price of commercial housing in Wenzhou. The National Bureau of Statistics of China calculates the current average price index of commercial housing through the ratio between the total price of commercial housing and the total area of commercial housing in the current phase. The fluctuation of the average price of commercial housing market can reflect the risks of real estate financial market to a large extent. As an important macroeconomic variable, GDP can accurately reflect the degree of regional economic development. The regional GDP level is the supporting strength for the development of real estate development in a region, and it has a great influence on the financial risks of the real estate market. Therefore, it is necessary to conduct empirical analysis as an explanatory variable.

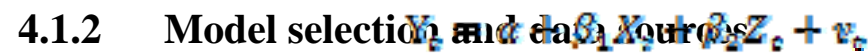

Model specification:

$\mathrm{Y}$ is explained variable: the concentration ratio of Wenzhou real estate loan is used to measure Wenzhou real estate financial risks; $\mathrm{X}$ and $\mathrm{Z}$ are explaining variables, which are the average price of commercial housing and the level of regional GDP respectively, representing the price level of Wenzhou real estate and the level of economic development; $v$ is error term, representing impact factors beyond our statistics.

Data source: the variables in the model are selected from Wenzhou Statistical Yearbook and 
China Real Estate Yearbook from 2001 to 2015.

\subsubsection{Empirical result and regression analysis}

Firstly, correlation coefficient analysis on $\mathrm{X}$ and $\mathrm{Z}$ is conducted. The correlation between $\mathrm{X}$ (the average price of commercial housing) and Z (regional GDP levels) is low, which shows that the possibility of colinearity is low. So the OLS Regression is feasible.

Table 1. OLS regression

\begin{tabular}{|c|c|c|}
\hline Variables & $\begin{array}{c}\text { The average price of commercial } \\
\text { housing }: \mathrm{X}\end{array}$ & $\mathrm{Z}$ \\
\hline $\begin{array}{c}\text { The average price of commercial } \\
\text { housing }: \mathrm{X}\end{array}$ & 1 & \\
\hline Regional GDP level $: \mathrm{Z}$ & 0.38 & 1 \\
\hline
\end{tabular}

According to the OLS Regression on selected variables through STATA 12.0, we get following regression result:

Table 2. Regression result

\begin{tabular}{|c|c|c|c|}
\hline \multirow{2}{*}{ Variables } & $\begin{array}{c}\text { The average price of commercial } \\
\text { housing }: \mathrm{X}\end{array}$ & $\begin{array}{c}\text { Regional GDP } \\
\text { level }: \mathrm{Z}\end{array}$ & $\begin{array}{c}\text { Constant } \\
\text { term }\end{array}$ \\
\hline \multirow{2}{*}{$\begin{array}{c}\text { The concentration ratio of Wenzhou } \\
\text { real estate loans }: \mathrm{Y}\end{array}$} & $-3.21 \mathrm{E}-6^{* *}$ & $1.04 \mathrm{E}-5^{*}$ & $0.043^{* * *}$ \\
\cline { 2 - 4 } & $(0.028)$ & $(0.053)$ & $(0.020)$ \\
\hline R-square & 0.6025 & & \\
\hline
\end{tabular}

Note: *** indicates that it's conspicuous at 1\% level; ** indicates that it's conspicuous at 5\% level; * indicates that it's conspicuous at $10 \%$ level.

$$
\begin{aligned}
& Y_{i}=0 . n 42-0 . n 0000321 X_{i}+n .0000104 z_{c} \\
& \begin{array}{lll}
(0.020) & (0.028) & (0.053)
\end{array} \\
& \mathrm{R}^{2}=0.6025 \text {; } \mathrm{P}=0.0628 \text { ； }
\end{aligned}
$$

(1) Because the P value in F-test is 0.0628 , the model is significant in general.

(2) $\mathrm{R}^{2}=60.25 \%$. The degree of the fitting of this model is relatively high.

(3) The $P$ value in t-test of variable $X$ is 0.028 , which shows that the significant level of $X$ is $5 \%$. That's to say, the average price of commercial housing has significantly negative 
correlation.

(4) The $\mathrm{P}$ value in t-test of variable $\mathrm{Z}$ is 0.053 , which shows that the significant level of $\mathrm{Z}$ is $10 \%$. That's to say, the regional GDP level has significantly positive correlation.

(5) In general, the risks of Wenzhou real estate are significantly affected by the average sale price of commercial housing and regional GDP level. And this contributes a lot to analyzing the risks of Wenzhou real estate. In particular, when preventing the risks of Wenzhou real estate, we should pay more attention to regulating the sale price of commercial housing.

\subsection{The assessment of Wenzhou real estate speculation}

The speculation in the real estate market has a great influence on $t$ real estate finance and regional economy. And it will also promote the price of real estate, so as to create bubbles in the capital market. In this regard, the evaluation of speculative degree of Wenzhou real estate market is conducive to the comprehensive analysis of the financial risks in Wenzhou real estate and prevents it effectively.

\subsubsection{The expected price of real estate}

According to existing literature, speculation in the real estate market mainly comes from the expectation of future real estate price fluctuations. Expected future real estate price includes two parts: one is the real estate price, assuming capital gains are zero; the other is the current value of expected capital gains, taking real estate as a kind of capital.

Therefore, the future price of the real estate market is expressed by the following formula: $P_{t}=P_{t}^{t}+H_{t} . P_{t}$ is the price of real estate in $\mathbf{t}$ phase; $P_{t}^{E}$ is the price of real estate when the capital gain is zero; $H_{t}$ is the expected present value of capital gains when taking real estate as a kind of asset. And the income $\mathbf{y}$ is correlated to the growth rate of land price $\mathbf{r}$, therefore it can be expressed by the following formula: $P_{\tau}^{E}=f\left(\mathrm{y}_{\mathrm{t}} \mathrm{r}_{\mathrm{t}}\right)$. Similarly, $H_{\mathrm{\tau}}$ is the concept of present value, so there is the following formula: $H_{t}=H_{t+1} /(1+r)$. Because real estate income is affected by the real estate price in the last phase, $g_{t-1}$ is used to represent the growth rate of land price in the previous phase. As a result, there is the following formula: $H_{t+1}-f\left(s_{t-1}\right)$. After the simple conversion through the above formulas, the expected price of future real estate is obtained:

$P_{t}=f_{1}\left(y_{v}, r_{t}\right)+f_{2}\left(g_{t-1}\right) /(1+r)(1)$ 


\subsubsection{The measure model of real estate speculation}

According to the expected price formula of future real estate, we make the approximate linearization of equation (1) to get the approximate linearization Equation:

$P_{t}=\alpha_{0}+\alpha_{1} y_{2}+\alpha_{2} r_{t}+\alpha_{3}\left[\frac{\sigma_{t-1}}{1+r_{t}}\right]_{t}+v_{\tau}$

Thereinto $\alpha_{0}+\alpha_{2} y_{1}+\alpha_{\Omega} x_{t}$ represents the price of real estate when the capital gain is

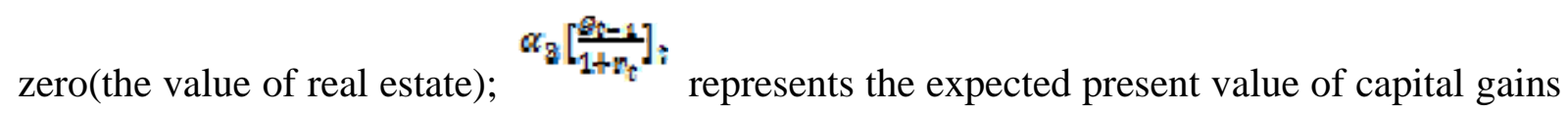
when taking real estate as a kind of asset (the inducement of the speculative behavior); $v_{t}$ is the stochastic error term.

\subsubsection{Model updating and data sources}

Because we mainly use the data to evaluate the speculation in Wenzhou real estate, considering that the actual situation the data, we simplify the model (equation (2)) to obtain:

$\ln P_{t}=\alpha_{0}+\alpha_{1} \ln y_{t}+\alpha_{2} \ln r_{t}+\alpha_{3} \ln P_{t-1}+v_{t} ;(3)$

Thereinto $\boldsymbol{P}_{\mathbf{z}}$ is the sale price of real estate in the current phase, and it is replaced by the average price of Wenzhou real estate when the model is estimated; $y_{t}$ represents per capita disposable income in the current phase. The per capita disposable income data of Wenzhou is selected when the model is estimated; $r_{t}$ is the current cost of real estate, and it is replaced by the ratio between the value of buildings completed and completed areas when the model is estimated.

In addition, according to the model hypothesis, $\alpha_{3}$ is the fluctuation of real estate price in the current phase when the fluctuation in the last phase is $1 \%$. And the fluctuation of real estate price in the current phase can be used to measure the speculation in real estate.

Data source: the variables in the model are selected from Wenzhou Statistical Yearbook and China Real Estate Yearbook from 2001 to 2015. 


\subsubsection{Empirical result and regression analysis}

Firstly, correlation coefficient analysis on $\mathrm{X}$ and $\mathrm{Z}$ is conducted. The correlation between $\mathrm{y}$ (per capita disposable income in the current phase) and $r$ (the current cost of real estate) is low, which shows that the possibility of colinearity is low. So the OLS Regression is feasible.

Table 3. OLS Regression

\begin{tabular}{|c|c|c|}
\hline Variables & Per capita disposable income in the & The current cost of real \\
\hline Per capita disposable income in the & current phase : $: \mathrm{r}$ \\
current phase $: \mathrm{y}$ & 1 & \\
\hline The current cost of real estate $: \mathrm{r}$ & 0.43 & 1 \\
\hline
\end{tabular}

According to the OLS Regression on selected variables through STATA 12.0, we get following regression result:

Table 4. Regression result

\begin{tabular}{|c|c|c|c|c|}
\hline \multirow{2}{*}{ Variables } & $\begin{array}{c}\text { Per capita disposable } \\
\text { income in the current } \\
\text { phase }\end{array}$ & $\begin{array}{c}\text { The current cost } \\
\text { of real estate }\end{array}$ & $\begin{array}{c}\text { The sale price of real } \\
\text { estate that lags one } \\
\text { phase }\end{array}$ & $\begin{array}{c}\text { Constant } \\
\text { term }\end{array}$ \\
\hline $\begin{array}{c}\text { The sale price of real } \\
\text { estate in the current } \\
\text { phase }\end{array}$ & $0.791 * *$ & $0.200 * * *$ & $1.440 * * *$ & $6.039 *$ \\
\hline R-square & $(0.049)$ & $(0.022)$ & $(0.002)$ & $(0.083)$ \\
\hline
\end{tabular}

Note: *** indicates that it's conspicuous at $1 \%$ level; ** indicates that it's conspicuous at $5 \%$ level; * indicates that it's conspicuous at $10 \%$ level.

$$
\begin{aligned}
& \ln P_{t}=6.039+0.791 \ln y_{t}+0.200 \ln r_{t}+1.440 \ln P_{t-1} \\
& (0.083) \\
& \mathrm{R}^{2}=0.9584 ; \mathrm{P}=0.0000 ;
\end{aligned}
$$

(1) Because the P value in F-test is 0.0000 , the model is very significant in general.

(2) $\mathrm{R}^{2}=95.84 \%$, close to $100 \%$. So the degree of fitting of this model is relatively high. 
(3) The P value in t-test of variable $\ln y_{t}$ is 0.049 , which shows that the significant level of $\ln y_{t}$ is $5 \%$. That's to say, per capita disposable income in the current phase has a significantly positive correlation with the sale price of real estate in the current phase.

(4) The P value in t-test of variable $\ln r_{\varepsilon}$ is 0.022 , which shows that the significant level of $\ln r_{\varepsilon}$ is $5 \%$. That's to say, the current cost of real estate has a significantly positive correlation with the sale price of real estate in the current phase.

(5) The $P$ value in t-test of variable $\ln P_{t-1}$ is 0.002 , which shows that the significant level of $\ln P_{t-1}$ is $1 \%$. That's to say, the cost of real estate in the last phrase has a significantly positive correlation with the sale price of real estate in the current phase.

(6) $\alpha_{8}=1.440127$, according to the research within and outside China, when the estimated value of $\alpha_{3}$ is more than 0.4 , the speculative degree of real estate is high. So there is serious speculation in Wenzhou real estate market.

(7) In general, the sale price of Wenzhou real estate consists of per capita disposable income in the current phase, the current cost of commercial housing and the sale price in the last phrase. And this has passed the statistical test. The estimated results show that in Wenzhou, if per capita disposable income in the current phase, the current cost of commercial housing and the sale price in the last phrase respectively increase $1 \%$, the price of commercial housing will increase $0.79 \%, 0.20 \%, 1.44 \%$ respectively.

\section{Conclusions and recommendations}

Through the above analysis and empirical results, we can know that declining sale price of real estate is the primary factor of increasing risks in Wenzhou real estate financial market. The level of speculation in Wenzhou real estate market is very high. The author puts forward the following suggestions for the above phenomenon:

(1) Wenzhou government should coordinate the development of Wenzhou real estate market, and strengthen land supply, housing information and price movement. These measures can guide people's expectations and rationality on house-purchase and make the development of the real estate market more benign. 
(2) Wenzhou government should regulate private the lending market. On the one hand, by publicity and education, people can have a good understanding of the dangers of usury. The registration system of private lending not only warns the risks, but also regulates private lending behavior. On the other hand, effective policies can guide private lending funds into the real economy; consequently, the supplementary function of private lending funds can be made use of effectively.

(3) Wenzhou government needs to formulate effective policies on the real estate market. Wenzhou real estate market bubbles are not completely caused by the housing shortage, so in the case of that the current house price continues to fall; the land supply can't be blindly increased. Instead, the government should properly control the transaction of state-owned land and the relevant project examination and approving, so as to decline the number of real estate, maintain a balance between supply and demand, change the decreasing trend of the house price. Thus house price can remain stable within a short time, and then the spread of real estate financial risks can be curbed.

\section{References}

Krugman P. (1999) “The role of geography in development”, International Regional Science Review, vol. 22, no. 2, pp. 142-161.

Li, L. Y. \& Li, W. (2012) "Game analysis on transition from real estate financial risk to landing fiscal risk in China”, Modern Finance and Economics-Journal of Tianjin University of Finance and Economics, no. 7, pp. 59-69.

Li, J. F. \& Shi, C. Y. (2005) “The empirical analysis of bank lending and property price volatility”, Journal of Shanghai University of Finance and Economics, vol. 7, no. 2, pp. 26-32.

Zhang, Y. "Economic research and relevant policies of China's real estate market", Dissertation, Xi'an University of Science and Technology, 2013.

Yi, X.R. (2007) “The trend of property market: from the year of 2006", Development Observation, no. 1, pp.40-49. 